\title{
A new Epipsocus (Psocodea: Psocomorpha: Epipsocidae) from the Brazilian Amazonia, with supernumerary forewing venation
}

\author{
Alfonso N. García Aldrete' (D) \& Alberto Moreira da Silva Neto² (D)
}

\begin{abstract}
1. Departamento de Zoología, Instituto de Biología, Universidad Nacional Autónoma de México, Apartado Postal 70-153, CdMx, México. (anga@ib.unam.mx)
2. Instituto Nacional de Pesquisas da Amazônia (INPA), Programa de Pós-Graduação em Entomologia, Campus II, Caixa Postal 478, 6901 1-97 Manaus, AM, Brazil. (bio.alberto@gmail.com)
\end{abstract}

Received 15 April 2019

Accepted 7 October 2019

Published 2 December 2019

DOI 10.1590/1678-4766e2019038

ABSTRACT. Epipsocus manausensis sp. nov., a new psocid species from state of Amazonas, Brazil is here described and illustrated. It differs from all the other species of the genus in having a crossvein between the pterostigma and Rs, in having R2+3 and R4+5 forked or with multiple branches, and in having M dichotomously branched or with multiple branches.

KEYWORDS. Psocids, Neotropics, Taxonomy.

Among the described species of Epipsocus Hagen, 1866 (LIENHARD \& SMITHERs, 2002), only E. fuscareolatus New, 1980, E. opticus New \& Thornton, 1988, E. moroni García Aldrete, 2019 and E. reyesi García Aldrete 2019 deviate from the pattern of caeciliusid forewing venation of the Epipsocus species (e.g., forewing M only with three primary branches and without secondary branches). In the first two species, the forewing $\mathrm{M}$ has four primary branches, and in the latter two species, the forewing $\mathrm{M}$ is three branched, with $\mathrm{M}_{3}$ forked, resulting in $\mathrm{M}_{3 \mathrm{a}}$ and $\mathrm{M}_{3 \mathrm{~b}}$ (GARCÍA AlDRETE, 2019).

We describe a new species of Epipsocus in which there is a crossvein between the pterostigma and Rs; R2+3 and $\mathrm{R} 4+5$ are branched, and M3 is dichotomously branched in the male, and forewing $\mathrm{M}$ is four branched, with $\mathrm{M}_{4}$ dichotomously branched in the female. Although the forewing venation deviates strongly from the Epipsocus species, it is assigned in this genus on the basis of genitalic male and female characters.

\section{MATERIAL AND METHODS}

One male and three females were studied. The specimens were dissected in $80 \%$ ethanol, and their parts (head, wings and antennae; the hind legs were missing) were mounted on slides in Canada balsam, following standard procedures. Parts on the slides were measured with a filar micrometer; abbreviations of parts measured are as follows: FW, HW: lengths of fore- and hind- wings; $f 1$...fn: lengths of flagellomeres $\mathrm{f} 1$...fn of right antenna; IO, D, and d: mínimum distance between compound eyes, antero-posterior and transverse diameter, respectively, of right compound eye, in dorsal view of head, PO: $\mathrm{d} / \mathrm{D}$. The type material are deposited in the Coleção de Invertebrados, Instituto Nacional de Pesquisas da Amâzonia, Manaus, Amazonas, Brazil.

\section{RESULTS}

\section{Epipsocus manausensis sp. nov.}

(Figs 1-9)

urn:lsid:zoobank.org:pub:81893BF3-DD4E-4AAC-A37DA810F567B02D

Diagnosis. Forewing with a crossvein between pterostigma and Rs. $\mathrm{R} 2+3$ and $\mathrm{R} 4+5$ forked, $\mathrm{M}_{3}$ in the male and $\mathrm{M}_{4}$ in the female dichotomously branched. Outer cusp of lacinial tip with a setal brush on outer posterior corner.

Male. Color (in $80 \%$ ethanol). Body pale brown. Compound eyes black, ocelli hyaline, with ochre centripetal crescents. Forewing (Fig. 1) mostly hyaline, area between C and $\mathrm{R}$ brown, basoradial cell brown. Pterostigma brown, veins brown, with a dark spot at wing margin, a dark area anteriorly in areola postica, between $\mathrm{Cu} 2$ and wing margin. Hindwings hyaline (Fig. 2). Abdomen pale brown, with irregular, ochre transverse subcuticular bands, less pigmented ventrally.

Morphology. Outer cusp of lacinial tips broad, with five denticles, and a brush of setae distally on outer corner. Forewing pterostigma broadly as an escalene triangle, with a slanted backwards crossvein from the lower angle to Rs. $\mathrm{R} 2+3$ and R4+5 dichotomously branched, with a vein stub anteriorly, near the inner arm of the $\mathrm{r} 2+3$ fork; $M$ of three primary branches, with $M_{3}$ forked, resulting in $M_{3 a}$ and $M_{3 b}$. 


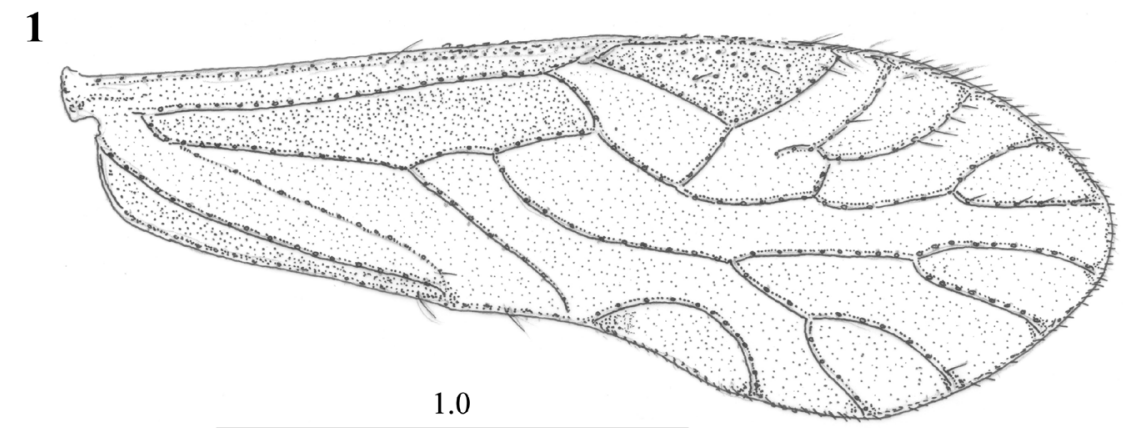

2
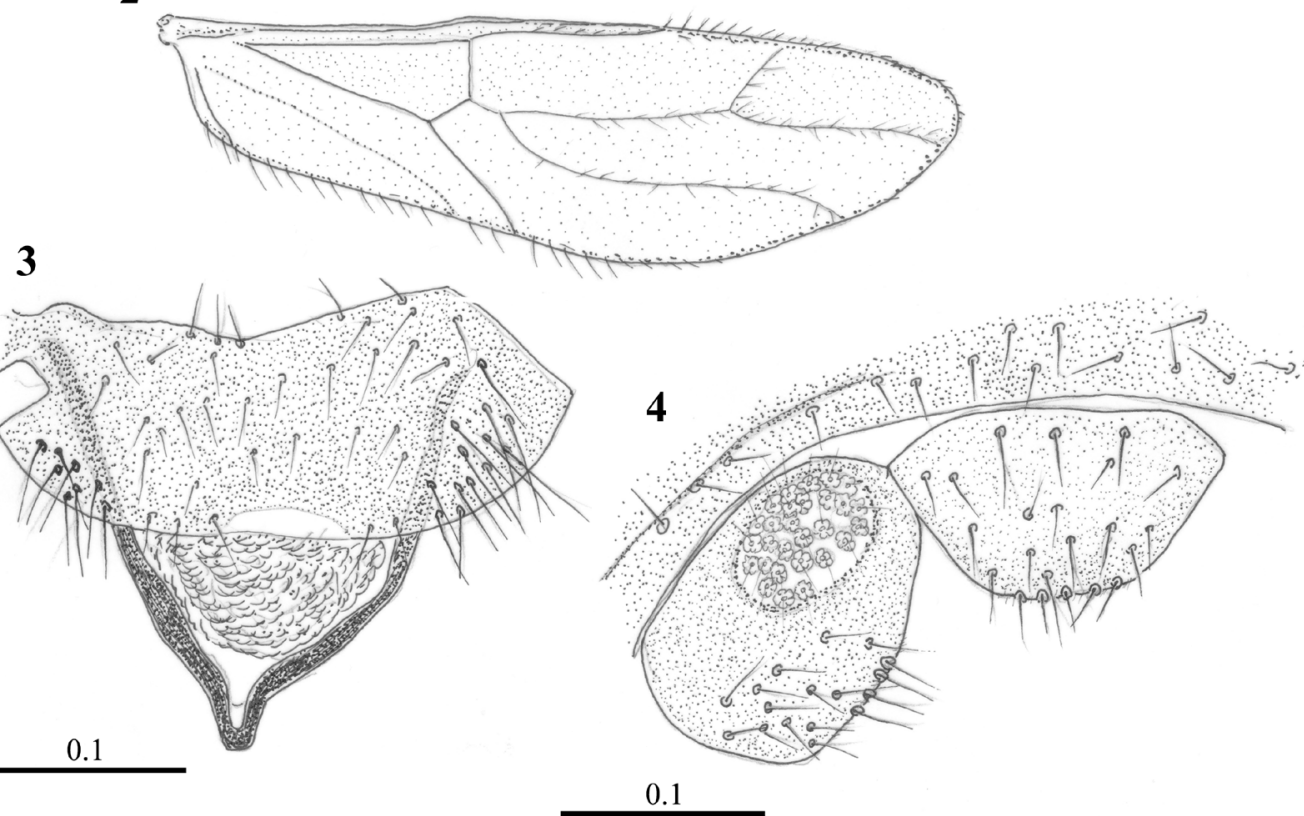

Figs 1-4. Epipsocus manausensis sp. nov., §ิ, male: 1, forewing; 2, hindwing; 3, hypandrium and phallosome; 4, posterior border of clunium, left paraproct and epiproct. Scales in mm. Figs 1, 2 to common scale.

Areola postica low, semicircular. Hindwing as illustrated (Fig. 2). Hypandrium (Fig. 3) broad, setose, posteriorly straight, with a field of setae on each postero-lateral corner. Phallosome (Fig. 3) with posterior projection of aedeagal arch narrow, endophallus membranous. Paraprocts (Fig. 4) broad, setose as illustrated, sensory fields large, elliptic, bearing 27-28 trichobothria on basal rosettes. Epiproct (Fig. 4) trapeziform, with three mesal macrosetae near anterior border, other setae as illustrated.

Measurements (in microns). FW: 2350, HW: 1796, f1: 551, f2: 477, IO: 189, D: 237, d: 188, IO/d: 1.0, PO: 0.79.

Female. Color (in $80 \%$ ethanol). Same as the male.

Morphology. Outer cusp of lacinial tip as in the male. Forewing venation (Fig. 5), pterostigma and crossvein to Rs as in the male, $\mathrm{R} 2+3$ forked, $\mathrm{R} 4+5$ with three branches; $M$ with four primary branches, with $\mathrm{M}_{4}$ forked, resulting in $M_{4 a}$ and $M_{4 b}$. Hindwing as in the male (Fig. 6). One female without pterostigma-Rs crossvein, $M$ with $M_{3}$ fused to $\mathrm{M}_{2}, \mathrm{R}_{1}$ and $\mathrm{R}_{2}$ fused medium and then separated (Fig. 7). Subgenital plate (Fig. 8) broad, setose, with sides converging to a pointed apex, pigmented area widely concave anteriorly.
Gonapophyses (Fig. 9): v1 long, slender, acuminate, v2+3 anteriorly with a blunt heel, v3 a distinct, elongate lobe bearing 7-8 long setae, distal process anteriorly dilated, posteriorly slender, acuminate, bearing microsetae. Ninth sternum membranous (Fig. 9), with spermapore posteriorly, surrouned by a pigmented rim. Paraprocts (Fig. 9) broad, setose as illustrated, sensory fields large, elliptic, bearing 24-25 trichobothria in basal rosettes. Epiproct (Fig. 9) trapeziform, with a row of setae posteriorly and three mesal macrosetae near anterior border, othar setae as illustrated.

Measurements (in microns). FW: 2448, HW: 1834, f1: 533, f2: 1834, IO: 300, D: 249, d: 159, IO/d: 1.88, PO: 0.63.

Type locality. Holotype $\hat{\sigma}$, Brazil, Amazonas: Manaus, Cd. Universitaria. January 1979, malaise trap, J. A. Rafael. Paratype + , same locality and collector as the holotype, 4-25.XI.1978, malaise trap. Paratype + , same locality and collector as the holotype. XII.1978, malaise trap, abdomen missing. Paratype $q$, same locality and collector as the holotype. January, 1979, malaise trap.

Etymology. The specific epithet refers to the type locality, Manaus, capital of state of Amazonas, Brazil. 
5

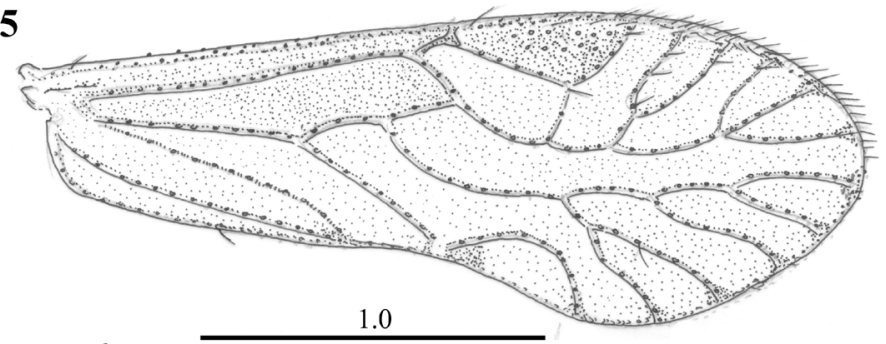

6
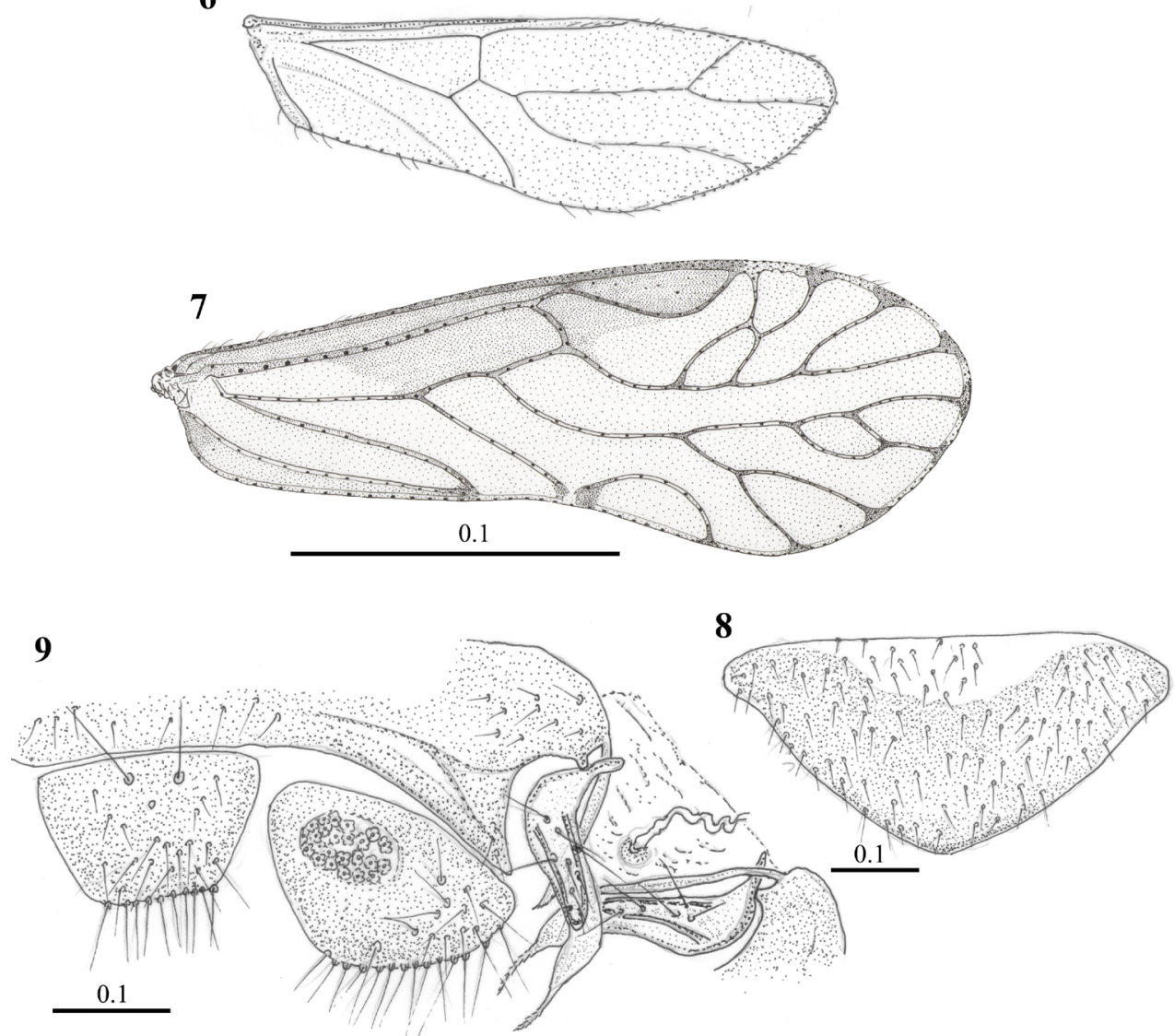

Figs 5-9. Epipsocus manausensis sp. nov.,,+ : 5, forewing; 6, hindwing; 7, Forewing venation of another female specimen; 8, subgenital plate; 9 , posterior border of clunium, epiproct, right paraproct, gonapophyses and ninth sternum. Scales in mm. Figs 5,6 to common scale.

\section{DISCUSSION}

Wing venation anomalies occur in species of Epipsocus (GARcía Aldrete, 2019). The species here described is unique because it has a crossvein between the pterostigma and Rs, and has multiple veins in $\mathrm{R} 2+3, \mathrm{R} 4+5$ and $\mathrm{M}$, clearly different from E. moroni from Costa Rica, and from $E$. reyesi from Mexico, which have R2 +3 and $\mathrm{R} 4+5$ unbranched, with $\mathrm{M}$ dichotomously branched.

Epipsocus manausensis sp. nov. is only known from the type locality. With the exception of $E$. fuscareolatus and E. opticus, which have the forewing $\mathrm{M}$ with four primary branches and without secondary branches, all the species of Epipsocus recorded in the Amazon basin (E. acanthus New, 1980; E. argutus New, 1980; E. atratus New, 1980; E. badonneli Mockford, 1991; E. blandus New \& Thornton, 1988; E. foliatus Mockford, 1991; E. maculithorax New, 1980; E. meruleus New, 1980; E. nepos Enderlein, 1900; E. pennyi New, 1980; E. pereirai Badonnel, 1974; E. phaeus New, 1980; E. roraimensis Mockford, 1991; E. stigmaticus Mockford, 1991; E. uniformis New, 1972; E. verrucosus New, 1980 and E. willineri New, 1972) have forewing venation caeciliusid.

Acknowledgments. AMSN thanks Instituto Nacional de Pesquisas da Amazônia (INPA) for research support. AMSN thanks particularly the support for the Capes-INPA research grant (Process \#88887.312051/2018-00). ANGA thanks Instituto de Biología, Universidad Nacional Autónoma de México, for continuous research support.

\section{REFERENCES}

García Aldrete, A. N. 2019. Two new species of Epipsocus Hagen, with forewing vein M3 forked (Psocodea: Psocomorpha: Epipsocidae). Dugesiana 26(1):35-40.

Lienhard, C. \& Smithers, C. N. 2002. Psocoptera. World Catalogue and Bibliography. Instrumenta Biodiversitatis V. Genève, Muséum national d'histoire naturelle. $745 \mathrm{p}$. 